\title{
In Vitro and in Vivo Antimicrobial Effects of Aloe Vera Fermented Hericium Erinaceum KU-1 for Food Borne Pathogens and Helicobacter Pylori
}

\author{
Dong Myong Kim ${ }^{1 *}$, Ju Yeong Jung ${ }^{1}$, Hyung Kon Lee ${ }^{1}$, Yong Seong Kwon', Yeon Mea Choi ${ }^{2}$, Hyo \\ Kyu Lee ${ }^{3}$, Youn Hee $\mathrm{Nam}^{3}$ and Tong Ho Kang ${ }^{3}$ \\ ${ }^{1} R \& D$ Center of KJM-Bio Ltd, 5F, 17, Saimdang-ro, Seocho-gu, Seoul, 06649, Korea \\ ${ }^{2}$ KimJeongMoon Aloe Ltd, 15, Saimdang-ro, Seocho-gu, Seoul, 06649, Korea \\ ${ }^{3}$ Department of Oriental Medicine Biotechnology, College of Life Sciences and Graduate School of Biotechnology, Kyung Hee University, \\ Global Campus, Gyeonggi 17104, Korea
}

*Corresponding author: Dong-Myong Kim, R\&D Center of KJM-Bio Ltd, 5F, 17, Saimdang-ro, Seocho-gu, Seoul, 06649, Korea

\section{ARTICLE INFO}

Received: 慧January 03, 2022

Published: 幽 January 13, 2022

Citation: Dong Myong Kim, Ju Yeong Jung, Hyung Kon Lee, Yong Seong Kwon, Yeon Mea Choi, et al., In Vitro and in Vivo Antimicrobial Effects of Aloe Vera Fermented Hericium Erinaceum KU-1 For Food Borne Pathogens and Helicobacter Pylori. Biomed J Sci \& Tech Res 41(1)-2022. BJSTR. MS.ID.006545

\section{ABSTRACT}

The aim of this study was to assess antimicrobial effect of an Aloe vera fermented Hericium erinaceum (HE) KU-1 condensate mixture (ALOHEM) using in vitro and in vivo models of food borne pathogens and Helicobacter pylori. The presence of ALOHEM effectively inhibited in vitro growth of food borne pathogens such as E. coli 0157:H7, S. aureus, L. monocytogenes, and S. enteritidis, whereas it did not inhibit the growth of $S$. enteritidis in $\mathrm{pH} 7.2$. The results of in vivo antimicrobial effects against $S$. enteritidis and H. pylori showed ALOHEM decreased the viable bacteria found in the feces and the mortality rate in $S$. enteritidis-infected mice. However, it did not affect gastric colonization of bacteria and histopathological lesions in H. pylori-infected mice, which is able to colonize the stomach by increasing the gastric $\mathrm{pH}$ through its urease production. These findings showed ALOHEM might have antimicrobial ability by decreasing $\mathrm{pH}$.

Keywords: Aloe vera; Hericium erinaceum; Fermentation; Food borne pathogens; Helicobacter pylori

\section{Introduction}

Aloe vera is most commonly known representative of aloe which belongs to the Liliaceae family and has been used as a remedy in many cultures. It is short-stemmed perennial and has leaves with sharp thorns. Aloe contains ingredients such as aloe ulcin, alomicin, aloetin, and aloesin, so it is widely known to have effects for antiulcer, anticancer, antiviral, antibacterial, and antifungal [1]. Hericium erinaceus is an edible mushroom and is used for gastrointestinal diseases by regulating gut microbiota and immune system [2]. It has the rich diterpenoid compounds, steroids, and polysaccharides and is known to have the antimicrobial activities against Helicobacter pylori, a human gastrointestinal pathogen $[3,4]$. As such, the mixture of the mycelium of Aloe vera and Hericium erinaceus was expected to have a strong antimicrobial effect, but it has not been studied yet. Therefore, we aimed to study the antimicrobial effects of Aloe vera fermented Hericium erinaceum KU-1 for food borne pathogens and Helicobacter pylori in vitro and in vivo. 
Food borne pathogens, such as E. coli, Salmonella and Listeria, are major causes of gastrointestinal disease worldwide. Enterohemorrhagic E. coli 0157:H7 causes hemorrhagic colitis, which is occasionally complicated by hemolytic uremic syndrome [5-7]. It is estimated that E. coli 0157:H7 infection causes over 73,500 cases of illness each year in the United States [8]. Salmonella spp. are facultative intracellular organisms that grow primarily inside the macrophages of the liver and spleen. S. enterica serovar Typhimurium is the most commonly isolated Salmonella serotype, accounting for $23 \%$ of laboratory confirmed Salmonella cases among the more than 1.4 million infections each year in the United States [9]. This infection is characterized by clinical symptoms such as fever, abdominal pain, and diarrhea in both animals and humans. Listeria monocytogenes is a gram-positive intracellular bacterium that is normally nonpathogenic in healthy individuals. However, in pregnant women, newborn infants, the debilitated elderly or immunocompromised people, it may cause severe clinical disease including meningoencephalitis, septicemia, or abortion [10-15].

It is estimated that L. monocytogenes infection causes about 2,000 to 2,500 cases of illness and as many as 500 deaths per year in the United States [16]. Helicobacter pylori is characterized by its typical corkscrew-like appearance and is at least twice as long as $H$. heilmannii [17], with a low infection rate of 0.08-1.0 \% in humans $[18,19]$. Its infection has been described mostly in relation to chronic gastritis [20,21], gastric ulcers [22] adenocarcinoma [23] and MALT lymphoma [24] in men. Antimicrobial chemotherapeutic agents have been widely used to control these gastrointestinal infections. However, widespread use of antibiotics is now being discouraged due to problems including the emergence of drugresistant strains and chronic toxicity [25]. In addition, antibiotics are often responsible for acute diarrhea due to the loss of normal intestinal microbes and the protection they provide against pathogenic organisms [26]. As alternatives, Hericium erinaceum (HE) such as KU-1 and their mycelium have been administered.

It is well known as lion's mane or monkey head mushroom have health-promoting attributes including antimicrobial properties [27-29], immunomodulation [30-33], anti-tumor characteristics [34-36], and hypocholesterolemic effects [37,38]. These findings have caught the attention of nutrition, food, and microbiology scientists and have heightened interests to produce functional foods. We isolated HE KU-1 and their mycelium from Pterocarpus indicus, and Cyclobalanopsis spp. This HE KU-1 was fermented in an appropriate Aloe vera broth, condensed by vacuum evaporation, and mixed with equal doses of each pathogenic strain. In this study, the antimicrobial effects of this HE KU-1 fermented condensate mixture (ALOHEM) were evaluated using in vitro and in vivo models of food borne pathogens and Helicobacter pylori.

\section{Materials and Methods}

\section{Microorganisms}

E. coli 0157H:7 ATCC 43894 (American Type Culture Collection, Rockville, MD, USA), Salmonella enteritidis CCARM 11066 (Culture Collection of Antibiotic Resistance Microbes, Seoul, Korea), Staphylococcus aureus (KFRI 240, Korea Food Research Institute, Wanju-gun, Jeollabuk-do, Korea), and Listeria monocytogenes ATCC 19115 and ATCC 51774, were used as pathogenic strains.

\section{Mycelial Culture}

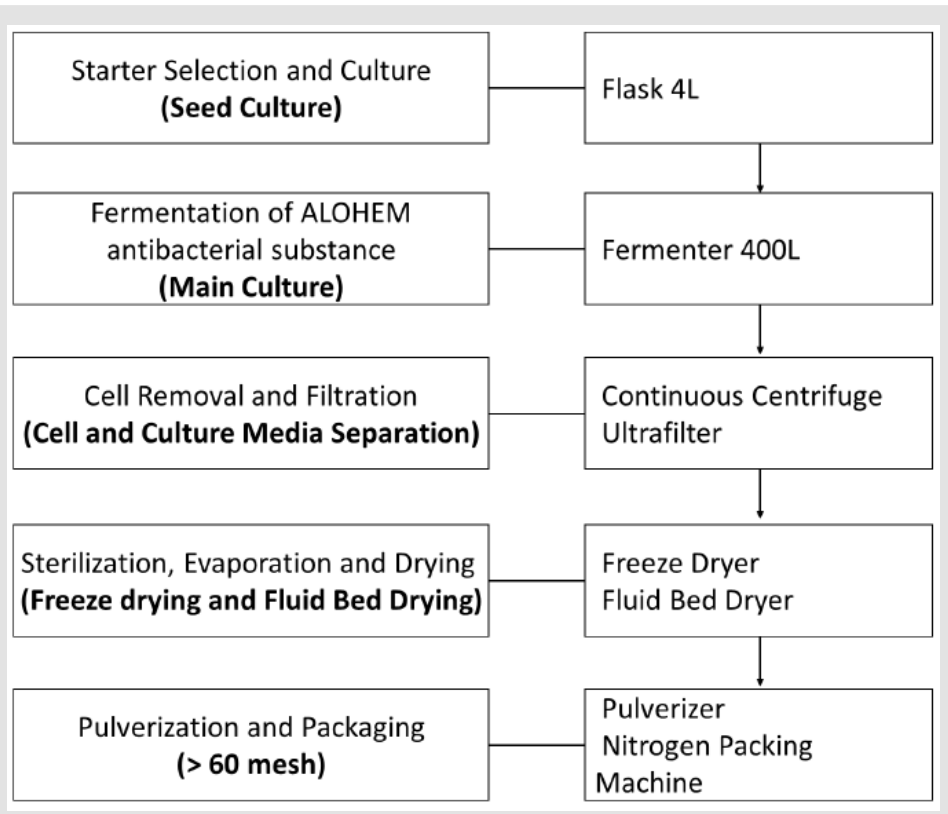

Figure 1: Manufacturing process of ALOHEM. 
The preparation process of ALOHEM is as shown in Figure 1. HE KU-1 mycelium was maintained on solid Ko medium [39] which is composed of glucose $18.02 \mathrm{~g}$, arginine $2.613 \mathrm{~g}$, ammonium acetate $2.613 \mathrm{~g}, \mathrm{CaCl}_{2} 0.33 \mathrm{~g}, \mathrm{KH}_{2} \mathrm{PO}_{4} 8.5 \mathrm{~g}, \mathrm{MgSO}_{4} \cdot 7 \mathrm{H}_{2} \mathrm{O} 2.0 \mathrm{~g}, \mathrm{FeSO}_{4} \cdot 7 \mathrm{H}_{2} \mathrm{O}$ $0.02 \mathrm{~g}, \mathrm{ZnSO}_{4} \cdot 7 \mathrm{H}_{2} \mathrm{O} 0.02 \mathrm{~g}, \mathrm{MnSO}_{4} \cdot 7 \mathrm{H}_{2} \mathrm{O} 0.02 \mathrm{~g}$, agar $18.0 \mathrm{~g}$ and distilled water $1 \mathrm{~L}$ at $\mathrm{pH}$ 4.5 5.0. A single colony of each HE KU-1 mycelium was inoculated into $10 \mathrm{~mL}$ of the Ko broth in a $15 \mathrm{~mL}$ conical tube and cultured in a shaking incubator (NB 205, N-Biotec, INC., Bucheon, Kyoungki-Do, Korea) at $200 \mathrm{rpm}$ and $28^{\circ} \mathrm{C}$ for $2 \sim 3$ days [39] HE KU-1 mycelia were fermented in Aloe vera broth on a jar-fermenter (CelliGen 115, Eppendorf, INC., NY, USA) at $150 \mathrm{rpm}$, $28^{\circ} \mathrm{C}$ for $3 \sim 4$ weeks. $99 \%$ of Aloe vera extract (Aloe vera gel $\mathrm{W}^{\circledR}$, KimJeong Moon Aloe Ltd., Jeju-Do, Korea) was tested.

\section{Preparation of Aloe vera Fermented Hericium erinaceum KU-1 Condensate Mixture (ALOHEM)}

Following fermentation period of $3-4$ weeks at $25 \sim 28^{\circ} \mathrm{C}$, the HE KU-1 mycelia were isolated from a single colony and tested for their inhibitory effects on various food-borne pathogens. The HE KU-1 mycelia were removed by centrifugation at 2,700 $\times$ g for 30 min and the fermented media was concentrated 20 fold into a solid content by vacuum evaporation. Each concentrated medium was mixed with an equal weight of Aloe vera extract and lyophilized. The final ALOHEMs were prepared by mixing each condensate of equal weight and stored at $4^{\circ} \mathrm{C}$ until use.

\section{Animals}

Five-week-old specific pathogen-free (SPF) female BALB/c mice (Seoul National University Laboratory Animal Center, Seoul, Korea) for S. enteritidis infection and ICR mice (Daehan-Biolink, Chungbuk, Korea) were used for $H$. pylori infections. They were housed in polycarbonate cages in isolators and fed a commercial pellet diet with water ad libitum. Food and water were removed from the cages 5 hours prior to inoculation of the bacteria and/or ALOHEM. All animal experimentation was performed in accordance with the laboratory animal guidelines of Korea University (Seoul, Korea).

\section{In vitro Assessment of Antimicrobial Effects of the ALOHEM}

Each pathogenic strain was grown to an optical density (OD) of $0.8-1.0$ at $600 \mathrm{~nm}$. Briefly, $200 \mu \mathrm{L}$ of each bacterium was added to conical tubes containing $10 \mathrm{~mL}$ of appropriate concentrations $(0,1.25,2.5,5,10 \%)$ of the ALOHEM in TS broth and incubated with shaking at $200 \mathrm{rpm}$ and $37^{\circ} \mathrm{C}$. And $1 \mathrm{~mL}$ of each culture was taken at $0,1,2,3,4,6$, and $8 \mathrm{~h}$ post incubation and centrifuged at $5,000 \mathrm{rpm}$ for $10 \mathrm{~min}$. The supernatants were discarded and the bacterial cells were floated in $1 \mathrm{~mL}$ of fresh TS broth. Finally, the OD was measured at $600 \mathrm{~nm}$. This process was repeated once. To determine whether the antimicrobial effects of the ALOHEM are due to $\mathrm{pH}$, tubes containing various concentrations of the ALOHEM were adjusted to $\mathrm{pH} 7.2$ by the addition of $\mathrm{NaOH}$. Subsequently, 200 $\mu \mathrm{L}$ of cultured $S$. enteritidis was added to each tube and incubated at $37^{\circ} \mathrm{C}$. OD was measured at $0,2,4,6$, and $8 \mathrm{~h}$ post incubation using the same method as the sample preparation described above. This process was not performed against the other pathogens.

\section{In vivo Assessment of Antimicrobial Effects of the ALOHEM}

For $S$. enteritidis infection models, $1 \mathrm{~mL}$ containing $5 \times 10^{7}$ CFU of $S$. enteritidis was added to each tube containing $9 \mathrm{~mL}$ of the ALOHEM at various concentrations $(2.5,5$, and $10 \%)$ or of the TS broth (positive control), vortex-mixed, and used as inocula. The mice were immediately administered with $0.5 \mathrm{~mL}$ of each inoculum $\left(2.5 \times 10^{6} \mathrm{CFU}\right.$ of $S$. enteritidis per mouse $)$ via the intragastric route while the negative control mice were administered with the same volume of TS broth. Subsequently, the mice of each treated group were administered with $0.5 \mathrm{~mL}$ of ALOHEM of their respective concentration once a day for 4 days and the mice of positive and negative groups received $0.5 \mathrm{~mL}$ of TS broth. Bacteria from fecal samples were counted by plating on XLD (Difco) agar at $12 \mathrm{~h}, 1,2$, 3 , and 4 days post-inoculation (pi) days and mortality was checked at 21 days pi.

H. pylori originating from pig's stomach had been kept in the gastric passage of mice [40]. Three $H$. heilmannii-infected mice were necropsied by cervical dislocation and the stomachs were collected. They were carefully opened and the gastric content was removed by washing with sterile phosphate buffered saline (PBS). The stomachs were then added to a conical tube containing $10 \mathrm{~mL}$ of sterile PBS, electrically homogenized (Ultra-turrax T25, Ika, Staufen, Germany), and the resulting mixture was used as an infective inoculum. Then $1 \mathrm{~mL}$ of the infective inoculum was added to each tube containing $9 \mathrm{~mL}$ of 2.5, 5, and 10\% ALOHEM or TS broth (positive control), respectively, and vortex-mixed. The mice were immediately administered $0.5 \mathrm{~mL}$ of each inoculum intragastrically while the negative control mice were administered the same volume of TS broth. Subsequently, the mice of each group were administered $0.5 \mathrm{~mL}$ of each concentration of the ALOHEM once a day for 2 months pi, at which time all mice were euthanized by cervical dislocation and necropsied. Their stomachs were collected, opened, and the gastric contents were removed as described above. The gastric samples were then fixed in $10 \%$ buffered formalin for 24 $\mathrm{h}$, processed, and embedded in paraffin wax as standard protocol. Sections measuring 2 micrometers each were prepared and stained with hematoxylin and eosin (H\&E) and modified Steiner's silver stain (Sigma, St. Louis, MI, USA) for histopathological examination and for the detection of $H$. heilmannii, respectively. 


\section{Results}

\section{Antimicrobial Effects in vitro of Various Concentration of ALOHEM}

The ability of the ALOHEM to inhibit the in vitro growth of food-borne pathogens was evaluated and the results are shown in Figure 2. Just before the pathogens were added to each tube, the $\mathrm{pH}$ levels of the solutions were measured at 4.03 (10\% ALOHEM), 4.32 (5\% ALOHEM), 4.96 (2.5\% ALOHEM), 6.02 (1.25\% ALOHEM), and 7.24 (0\% ALOHEM). The growth of all strains except E. coli 0157:H7 was completely inhibited by the presence of the ALOHEM at concentrations above $2.5 \%$. All strains except $L$. monocytogenes ATCC 51774 began to grow in the broth containing the concentration of $2.5 \%$ ALOHEM 2 to $4 \mathrm{~h}$ post incubation, although the growth rate was lower than that of the control broth (0\% ALOHEM) (Figure 2A$2 \mathrm{E}$ ). However, when the $\mathrm{pH}$ of the broth was adjusted to 7.2 , the presence of the ALOHEM at any concentration did not inhibit the growth of $S$. enteritidis at all (Figure 2F).
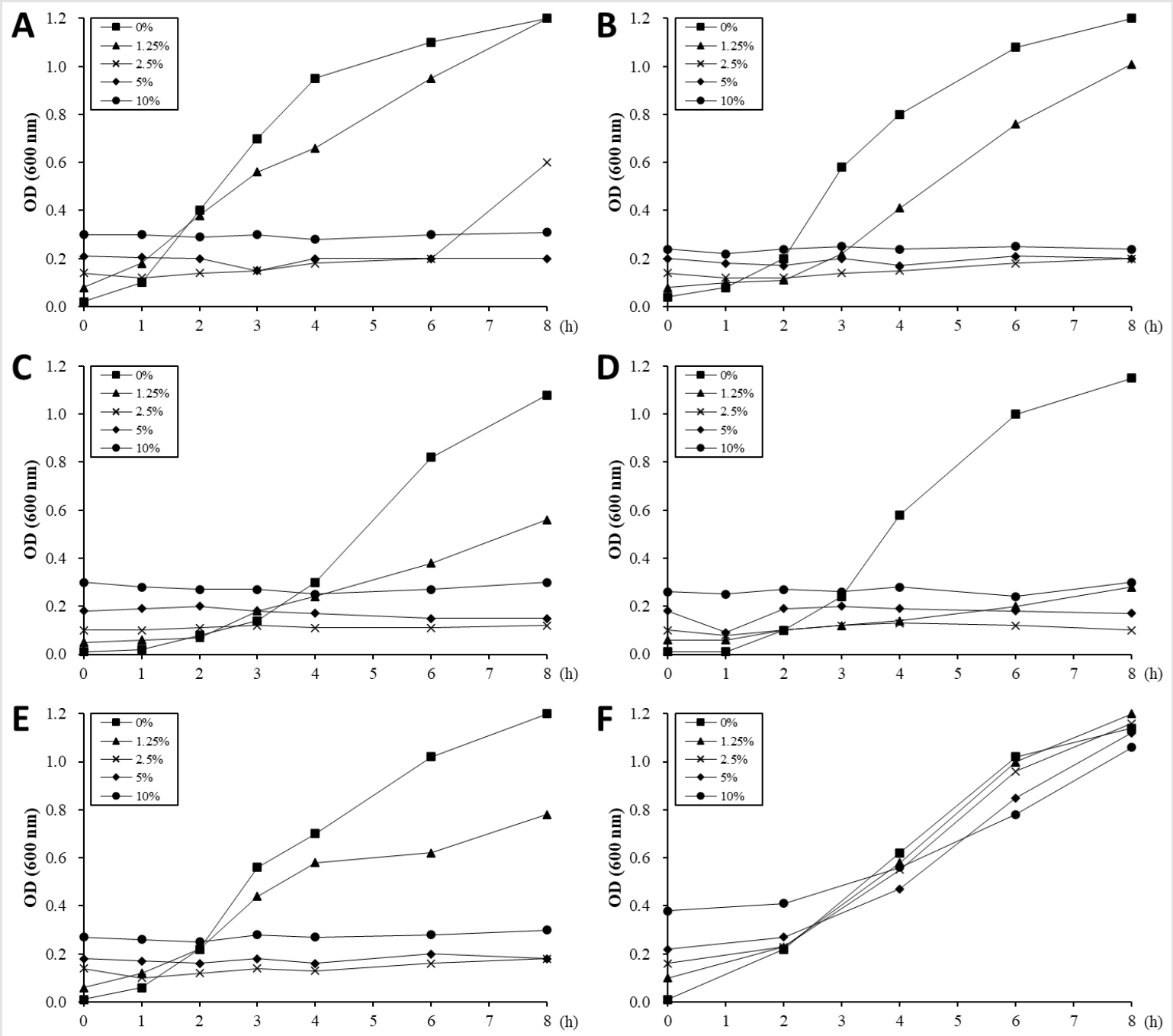

Figure 2: In vitro growth of E. coli O157:H7 (A), S. aureus (B), L. monocytogenes ATCC 19115 (C), L. monocytogenes ATCC 51774 (D), S. enteritidis (E) was inhibited by the presence of ALOHEM. Data show the mean value of two experiments performed. At the initial time of experiment, the $\mathrm{pH}$ of each broth containing $0 \%(-\mathbf{-}-), 1.25 \%\left(-\boldsymbol{\Delta}_{-}\right), 2.5 \%(-\mathbf{x}-), 5 \%\left(-\mathbf{-}_{-}\right)$, and $10 \%(-\bullet-)$ ALOHEM was 7.24, 6.02, 4.96, 4.32, and 4.03, respectively. Another experiment was performed to clarify the effects of pH on the antimicrobial ability of the ALOHEM (F). Each broth containing the different concentrations of the ALOHEM was adjusted to $\mathrm{pH} 7.2$ with $\mathrm{NaOH}$. Because the ALOHEM brings about a brown hue, optical density depended on the concentration of the ALOHEM at the start of the experiment $(0 \mathrm{~h})$. 


\section{Bacteria Count Evaluation by ALOHEM}

Antimicrobial effect of the ALOHEM against $S$. enteritidis and H. heilmannii infection was assessed in BALB/c and ICR mice, respectively. Table 1 shows the viable bacterial count from the fecal samples. The number of isolated bacteria was dose-dependently less in the mice inoculated with an admixture of the ALOHEM and the bacteria than in the mice that received only the bacteria (positive control). However, bacteria were steadily isolated in the mice that received $2.5 \%$ and $5 \%$ ALOHEM over the first 4 days. Bacteria were isolated from only one mice of the group administered with $10 \%$ ALOHEM 4 days following injection. The limitation of the bacterial count was $4.00 \log _{10} \mathrm{CFU} / \mathrm{g}$ feces.

Table 1: Bacterial counts from fecal samples.

\begin{tabular}{|c|c|c|c|c|c|}
\hline \multirow{2}{*}{ Treated with } & \multicolumn{5}{|c|}{$\log _{\mathbf{1 0}}$ CFU/g feces } \\
\cline { 2 - 6 } & $\mathbf{1 2 ~ h}$ & $\mathbf{1 ~ d}$ & $\mathbf{2 ~ d}$ & $\mathbf{3 ~ d}$ & $\mathbf{4 ~ d}$ \\
\hline Positive control & $5.40-5.61(5)^{\mathrm{a}}$ & $4.60-6.09(5)$ & $4.84-5.61(5)$ & $5.32-5.61(5)$ & $4.60-6.36(5)$ \\
\hline Bact in 2.5\% ALOHEM & $4.00-5.25(4)$ & $4.00-4.84(4)$ & $4.48-5.04(5)$ & $5.20-5.67(5)$ & $4.00-5.18(5)$ \\
\hline Bact in 5\% ALOHEM & $4.30-4.84(5)$ & $4.00-4.30(2)$ & $4.30-4.60(2)$ & $4.30-4.78(4)$ & $4.00-4.60(3)$ \\
\hline Bact in 10\% ALOHEM & $0(0)$ & $0(0)$ & $0(0)$ & $0(0)$ & $4.00(1)$ \\
\hline
\end{tabular}

${ }^{a}$ Values in parentheses represent the number of mice from which bacteria were isolated. All groups originally consisted of five mice.

\section{Assessment of Mortality by ALOHEM}

Mortality was assessed for 28 days pi. Daily administration of the ALOHEM or TS broth in each group was terminated when the first mortality occurred in the positive control group on day 5 pi. All mice of the positive control group died within 7 days of injection
(Figure 3). Although all mice in the 2.5 and 5\% ALOHEM treated group eventually died, mortality occurred between 9- and 11-days pi, later than that of the positive control group. Within the $10 \%$ ALOHEM treated group, one mouse died on day 14 pi and another on day 18 pi, while the rest survived until 21 days pi (Figure 3).

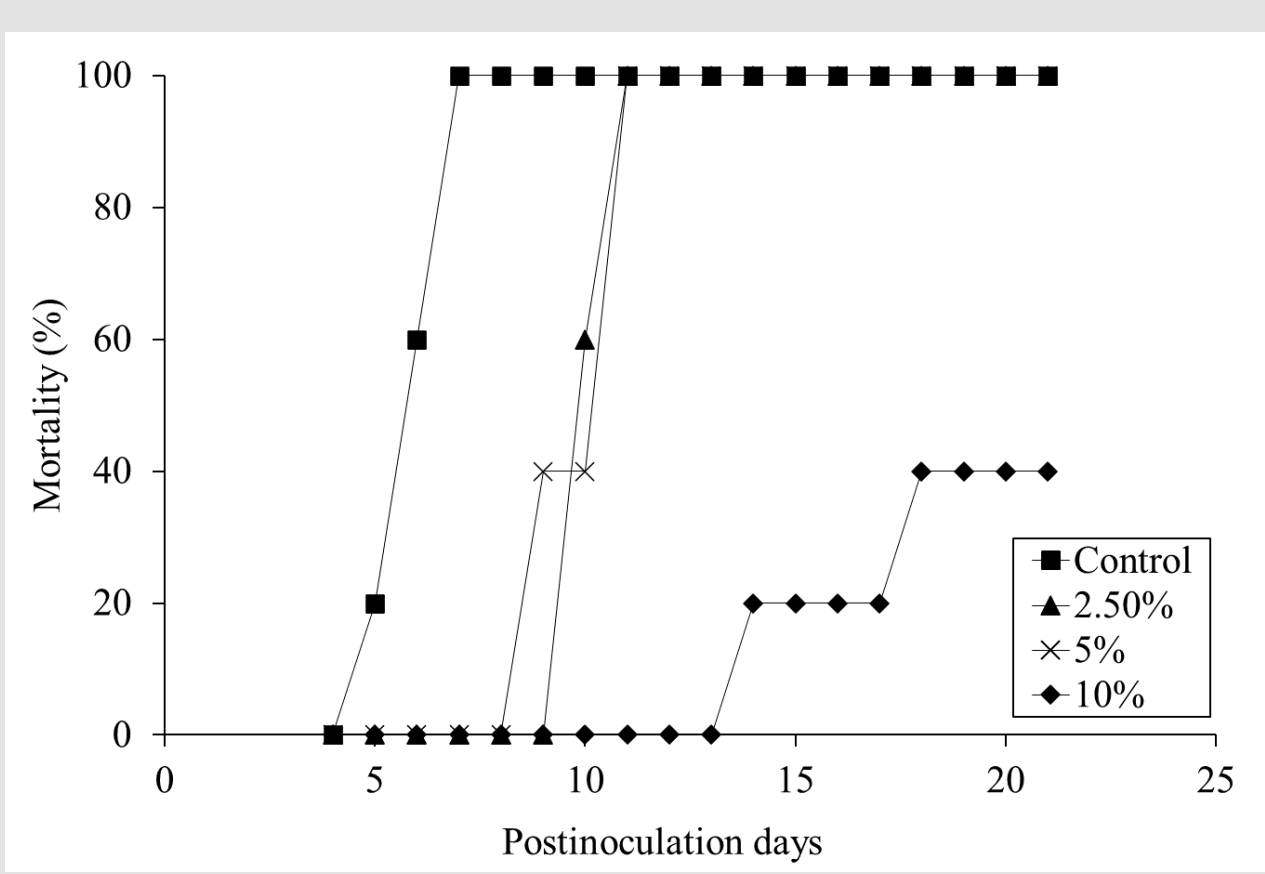

Figure 3: Mortality of the mice dosed with S. enteritidis throughout the experimental periods; the positive control group (-口-), $2.5 \%(-\mathbf{\Delta}-), 5 \%(-\mathbf{x}-)$, and $10 \%(-\bullet-)$ ALOHEM treated groups.

\section{The Histopathological and Microbiological Findings}

Table 2 summarizes the histopathological and microbiological findings. The results show that the use of ALOHEM did not suppress the bacterial colonization and histological lesions in the stomach at all. 
Table 2: Histopathological and microbiological findings of the mice stomachs ${ }^{\mathrm{a}}$.

\begin{tabular}{|c|c|c|c|c|c|}
\hline \multirow{2}{*}{ Groups } & \multicolumn{4}{|c|}{ Histopathological Findings } & \multirow{2}{*}{ Microbiologyc } \\
\cline { 2 - 5 } & \multicolumn{2}{|c|}{ Inflammation $^{\mathbf{2}}$} & Lymphoid Follicles & \multirow{2}{*}{ Cystic Change } \\
\cline { 2 - 5 } & Fundus & Pylorus & $0 / 6$ & $0 / 6$ & $0 / 6$ \\
\hline Negative control & $0 / 6$ & 6-Mar & 6-May & 6-Mar & 6-Jun \\
\hline Positive control & 6-May & & & 6-Mar & 6-Jun \\
\hline treated with & & 6-Mar & 6-Apr & 6-Feb & 6-Jun \\
\hline 2.5\% ALOHEM & 6-Jun & 6-Apr & 5-Apr & 5-Mar & 5-May \\
\hline 5\% ALOHEM & 6-Apr & 5-Mar & &
\end{tabular}

a expressed as number of detected mice/ number of tested mice.

${ }^{b}$ consisted of infiltration of mononuclear cells in lamina propria and submucosa.

cassessed by Steiner's silver stain.

\section{Histological Lesions}
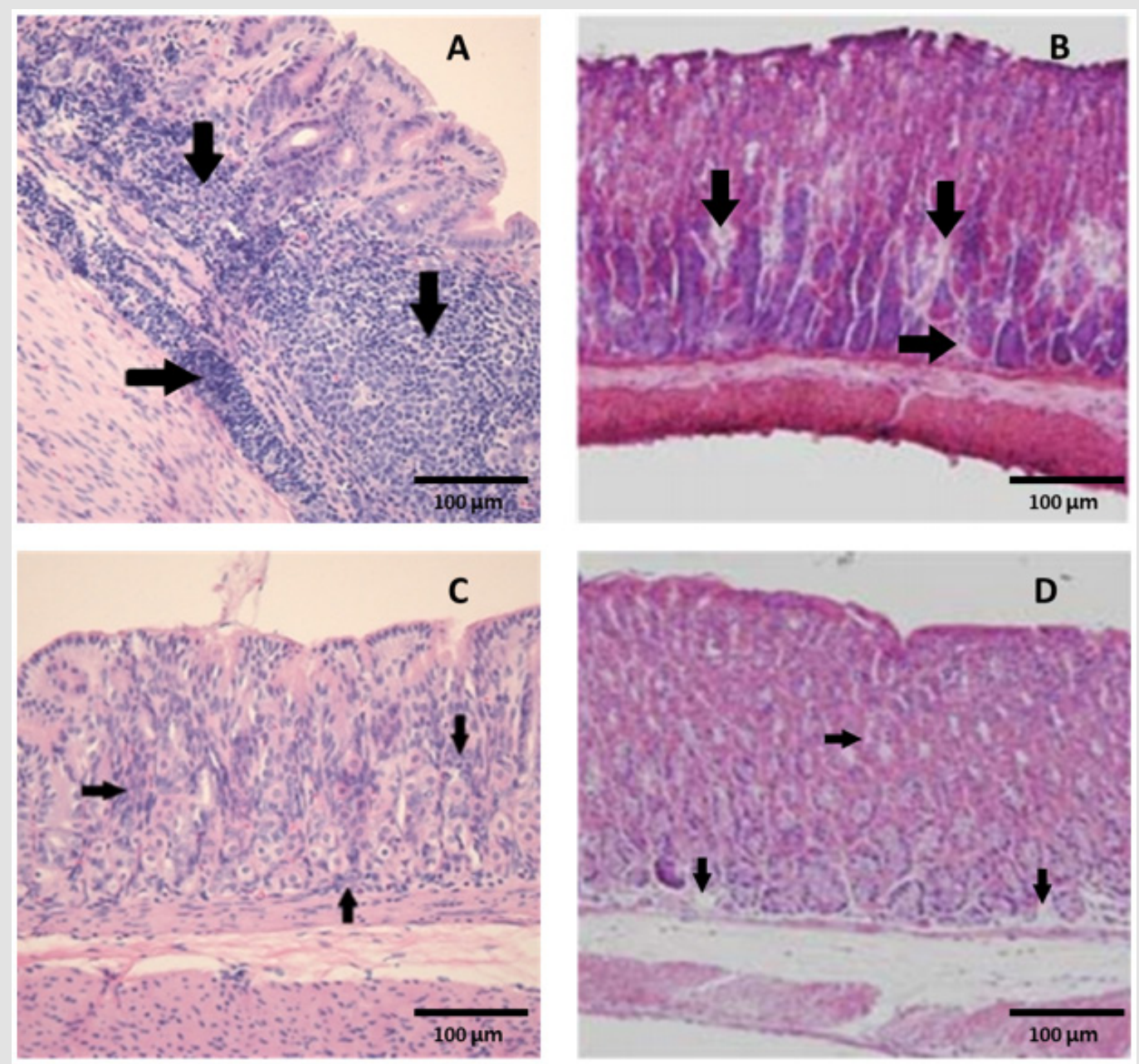

Figure 4: Marked colonization (arrows) of H. heilmannii in the lumen of the gastric glands of (A) a positive control mouse and (B) a mouse inoculated with an admixture of 10\% ALOHEM and H. heilmannii. (C) Infiltration of mononuclear cells and (D) presence of lymphoid follicle in the submucosa of the gastric body of mice inoculated with the admixture of $10 \%$ ALOHEM and H. heilmannii. A, B, C; Bar $=250 \mu \mathrm{m}, \mathrm{D} ; \mathrm{Bar}=62.5 \mu \mathrm{m}$. 
Regardless of the concentration of the ALOHEM treatment, marked colonization of $H$. heilmannii was observed in the lumen of the gastric glands, gastric pits, mucosal surfaces, and intercellular spaces of all infected mice (Figure 4A\&4B). Histological lesions such as the formation of lymphoid follicles, cystic changes, and mild inflammation in the mucosa or submucosa were randomly observed (Figure 4C\&4D). No bacteria and histological lesions were observed in the negative control group.

\section{Discussion}

Many studies have recently shown that Hericium erinaceum have antimicrobial effects. The potential mechanisms by which mushrooms might exert their antimicrobial activity includes the production of hericenone, other metabolites such as hydrogen peroxide and short chain fatty acids, and specific antimicrobial compounds such as antibiotics $[41,29,38]$. In the present study, we have shown that the ALOHEM effectively inhibits the in vitro growth of enteropathogens such as E. coli 0157 H:7, S. enteritidis, S. aureus, and L. monocytogenes. In vivo experimentation also revealed that the presence of $10 \%$ ALOHEM increased the survival rate of mice infected with $S$. enteritidis. In addition, the survival time of the 2.5 and 5\% ALOHEM groups was extended beyond that of the positive control group, even though all mice died within 11 days pi.

This might be because the presence of 2.5 and 5\% ALOHEM did not completely inhibit the growth of $S$. enteritidis and the bacterial growth rapidly progressed after the ALOHEM administration was terminated (4 days pi). Also, the presence of the ALOHEM did not inhibit the colonization of $H$. heilmannii in the stomach. These divergent results made it difficult to identify the antimicrobial mechanism of the ALOHEM. We first considered the low $\mathrm{pH}$ due to the hericenone as the factor, because the $\mathrm{pH}$ of each broth was in inverse proportion to the concentration of the ALOHEM. Based on this consideration, the $\mathrm{pH}$ of each broth was adjusted to 7.2 by the addition of $\mathrm{NaOH}$ and $200 \mu \mathrm{L}$ of an overnight culture of $S$. enteritidis was subsequently added to each broth. As a result, bacterial growth was not inhibited in any of the broths. This finding indicates that the antimicrobial effects of the ALOHEM might be due to low $\mathrm{pH}$, which is also the reason that the presence of the ALOHEM did not inhibit the colonization of $H$. heilmannii in the stomach. $H$. heilmannii is able to colonize the stomach by increasing the gastric $\mathrm{pH}$ through its urease production.

Therefore, it is likely that $H$. heilmannii mixed with $10 \%$ ALOHEM could survive at a low $\mathrm{pH}$ level by producing urease and colonizing the stomach. Previous findings [41] have shown that some hericenone produce by Hericium erinaceum spp, although able to inhibit a variety of pathogenic bacteria, do not inhibit the growth of both Salmonella sp. and Vibrio cholerae, when the effect of acids was excluded. Our preliminary study also shows that long periods of ALOHEM administration did not affect clinical signs, or the gross and histopathological lesions of the mice (data not shown), indicating that its ingestion might not pose health risks to humans and in fact be effective in preventing infections due to food borne pathogens.

\section{Conclusion}

This study was investigated the antimicrobial effect of an Aloe vera fermented Hericium erinaceum (HE) KU-1 condensate mixture (ALOHEM) using in vitro and in vivo models of food borne pathogens and Helicobacter pylori. The presence of the ALOHEM effectively inhibited in vitro growth of food borne pathogens such as E. coli 0157:H7, S. aureus, L. monocytogenes, and S. enteritidis. However, when the $\mathrm{pH}$ of the broth was adjusted to 7.2, the ALOHEM did not inhibit the growth of $S$. enteritidis at all. The in vivo antimicrobial effects of the ALOHEM against $S$. enteritidis and H. pylori were also assessed. In $S$. enteritidis-infected mice, the ALOHEM decreased the viable bacteria found in the feces and the mortality rate. However, it did not affect the gastric colonization of bacteria and histopathological lesions in mice infected with $H$. pylori, which is able to colonize the stomach by increasing the gastric $\mathrm{pH}$ through its urease production. These findings showed that the ALOHEM might have antimicrobial ability by decreasing $\mathrm{pH}$.

\section{Acknowledgement}

This work was supported by the Ministry of SMEs and Startups (MSS, Korea) under Grant the Technology development Program [number S3049433].

\section{References}

1. Sánchez M, E González Burgos, I Iglesias, MP Gómez Serranillos (2020) Pharmacological update properties of aloe vera and its major active constituents. Molecules 25(6): 1324.

2. Diling CY, Xin Y, Z Chaoqun, Jian Y, Xiaocui T, et al. (2017) Extracts from Hericium erinaceus relieve inflammatory bowel disease by regulating immunity and gut microbiota. Oncotarget 8(49): 85838- 85857.

3. Khan MA, M Tania, R Liu R, Rahman MM (2013) Hericium erinaceus: An edible mushroom with medicinal values. Journal of Complementary and Integrative Medicine 10(1): 253-258.

4. Zhu Y, Chen Y, Q Li, T Zhao, M Zhang, et al. (2014) Preparation, characterization, and anti-Helicobacter pylori activity of bi $3^{+}$-Hericium erinaceus polysaccharide complex. Carbohydrate Polymers 110: 231237.

5. Kelly J, Oryshak A, Wenetsek M, Grabiec J, Handy S (1990) The colonic pathology of Escherichia coli 0157: H7 infection. The American journal of surgical pathology 14(1): 87-92.

6. Morrison DM, Tyrrell DL, Jewell LD (1986) Colonic biopsy in verotoxinInduced hemorrhagic colitis and thrombotic thrombocytopenic purpura (ttp). American journal of clinical pathology 86(1): 108-112.

7. Neill MA, PI Tarr, CR Clausen, DL Christie, RO Hickman (1987) Escherichia coli 0157: H7 as the predominant pathogen associated with the hemolytic uremic syndrome: A prospective study in the pacific northwest. Pediatrics 80(1): 37-40. 
8. Mead PS, Slutsker L, Dietz V, Mccaig LF, Bresee JS, et al. (1999) Foodrelated illness and death in the United States. Emerging infectious diseases 5(5): 607 .

9. (2001) Control, C.F.D. and Prevention Outbreaks of multidrug-resistant Salmonella typhimurium associated with veterinary facilitiesidaho, minnesota, and washington, 1999. MMWR. Morbidity and mortality weekly report 50(33): 701-704.

10. Bach MC, Davis KM (1987) Listeria rhombencephalitis mimicking tuberculous meningitis. Clinical Infectious Diseases 9(1): 130-133.

11. Gray ML, Killinger A (1966) Listeria monocytogenes and listeric infections. Bacteriological reviews 30(2): 309-382.

12. Ho JL, KN Shands, G Friedland, Eckind P, DW Fraser (1986) An outbreak of type $4 \mathrm{~b}$ Listeria monocytogenes infection involving patients from eight boston hospitals. Archives of Internal Medicine 146(3): 520-524.

13. Macdonald TT, Carter PB (1980) Cell-mediated immunity to intestinal infection. Infection and immunity 28(2): 516-523.

14. Marco A, Domingo M, Prats M, Briones V, Pumarola M, et al. (1991) Pathogenesis of lymphoid lesions in murine experimental listeriosis. Journal of comparative pathology 105(1): 1-15.

15. Marco A, Ramos J, Dominguez L, Domingo M, Gonzalez L (1988) Immunocytochemical detection of Listeria monocytogenes in tissue with the peroxidase-antiperoxidase technique. Veterinary pathology 25(5): 385-387.

16. Notermans S, Dufrenne J, Teunis P, Chackraborty T (1998) Studies on the risk assessment of Listeria monocytogenes. Journal of food protection 61(2): 244-248.

17. Andersen L, Boye K, Blom J, Holck S, Nørgaard (1999) Characterization of a culturable "gastrospirillum hominis" (Helicobacter heilmannii) strain isolated from human gastric mucosa. Journal of Clinical Microbiology 37(4): 1069-1076.

18. Dent J, Mcnulty C, Uff J, Wilkinson S, M Gear, et al. (1987) Spiral organisms in the gastric antrum. Lancet (London, England) 2(8550): 96-96.

19. Heilmann K, Borchard F (1991) Gastritis due to spiral shaped bacteria other than Helicobacter pylori: Clinical, histological, and ultrastructural findings. Gut 32(2): 137-140.

20. Ierardi E, Monno R, Gentile A, Francavilla R, Burattini O, et al. (2001) Helicobacter heilmannii gastritis: A histological and immunohistochemical trait. Journal of clinical pathology 54(10): 774777.

21. Kaklikkaya N, Ozgur O, Aydin F, Cobanoglu U (2002) Helicobacter heilmannii as causative agent of chronic active gastritis. Scandinavian journal of infectious diseases 34(10): 768-770.

22. Sykora J, V Hejda, Varvarovská J, Stozicky F, Gottrand F, et al. (2003) Helicobacter heilmannii related gastric ulcer in childhood. Journal of pediatric gastroenterology and nutrition 36(3): 410-413.

23. Morgner A, Bayerdörffer E, Meining A, Stolte M (1995) Helicobacter heilmannii and gastric cancer. Lancet (London, England) 346(8973): 511-512.

24. Regimbeau C, Karsenti D, Durand V, D’alteroche L, Copie Bergman C, et al. (1998) Low-grade gastric malt lymphoma and Helicobacter heilmanni (gastrospirillum hominis. Gastroenterologie clinique et biologique 22(89): 720-723.

25. Dundas S, J Murphy, Soutar R, Jones G, Hutchinson S, et al. (1999) Effectiveness of therapeutic plasma exchange in the 1996 lanarkshire Escherichia coli 0157: H7 outbreak. The Lancet 354(9187): 1327-1330.
26. Van Der Waaij D, H Hofstra, N Wiegersma (1982) Effect of $\beta$-lactam antibiotics on the resistance of the digestive tract of mice to colonization. Journal of Infectious Diseases 146(3): 417-422.

27. Friedman M (2015) Chemistry, nutrition, and health-promoting properties of Hericium erinaceus (lion's mane) mushroom fruiting bodies and mycelia and their bioactive compounds. Journal of agricultural and food chemistry 63(32): 7108-7123.

28. Lai PL, M Naidu, V Sabaratnam, KH Wong, RP David, et al. (2013) Neurotrophic properties of the lion's mane medicinal mushroom, Hericium erinaceus (higher basidiomycetes) from malaysia. International journal of medicinal mushrooms 15(6): 539-544.

29. Shang X, Q Tan, R Liu, K Yu, P Li, et al. (2013) In vitro anti-Helicobacter pylori effects of medicinal mushroom extracts, with special emphasis on the lion's mane mushroom, Hericium erinaceus (higher basidiomycetes). International journal of medicinal mushrooms 15(2): 165-174.

30. Lee JS, KM Min, JY Cho, EK Hong (2009) Study of macrophage activation and structural characteristics of purified polysaccharides from the fruiting body of Hericium erinaceus. Journal of microbiology and biotechnology 19(9): 951-959.

31. Lee JS, JY Cho, EK Hong (2009) Study on macrophage activation and structural characteristics of purified polysaccharides from the liquid culture broth of Hericium erinaceus. Carbohydrate Polymers 78(1): 162168.

32. Sheu SC, Y Lyu, MS Lee, Cheng JH (2013) Immunomodulatory effects of polysaccharides isolated from Hericium erinaceus on dendritic cells. Process Biochemistry 48(9): 1402-1408.

33. Yeh SP, LF Hsia, CS Chiu, ST Chiu, CH Liu (2011) A smaller particle size improved the oral bioavailability of monkey head mushroom, Hericium erinaceum, powder resulting in enhancement of the immune response and disease resistance of white shrimp, litopenaeus vannamei. Fish \& shellfish immunology 306: 1323-1330.

34. Kim SP, MY Kang, JH Kim, SH Nam, M Friedman (2011) Composition and mechanism of antitumor effects of Hericium erinaceus mushroom extracts in tumor-bearing mice. Journal of agricultural and food chemistry 59(18): 9861-9869.

35. Li G, K Yu, F Li, K Xu, J Li, et al. (2014) Anticancer potential of Hericium erinaceus extracts against human gastrointestinal cancers. Journal of ethnopharmacology 153(2): 521-530.

36. Wang JC, SH Hu, CH Su, TM Lee (2001) Antitumor and immunoenhancing activities of polysaccharide from culture broth of Hericium spp. The Kaohsiung journal of medical sciences 17(9): 461-467.

37. Jang HS, KN Yoon (2017) The antihyperlipidemic effect of lion's mane mushroom (Hericium erinaceus) in hyperlipidemic rats induced by high fat and cholesterol diet. Korean Journal of Clinical Laboratory Science 49(3): 263-270.

38. Yang BK, JB Park, CH Song (2003) Hypolipidemic effect of an exobiopolymer produced from a submerged mycelial culture of Hericium erinaceus. Bioscience, biotechnology, and biochemistry 67(6): 12921298.

39. Ko HG, DM Kim, WM Park (1997) Composition of a new medium for mycelial growth of Hericium erinaceus. The Korean Journal of Mycology 25(4): 369-376.

40. Park JH, J Hong, J Park (2003) Experimental infection of mice with tightly coiled spiral bacteria ("Candidatus helicobacter suis") originating from the pig stomach. Journal of comparative pathology 129(2-3): 154-160.

41. Kim DM, CW Pyun, HG Ko, WM Park (2000) Isolation of antimicrobial substances from Hericium erinaceum. Mycobiology 28(1): 33-38. 


\section{ISSN: 2574-1241}

DOI: 10.26717/BJSTR.2022.41.006544

Dong Myong Kim. Biomed J Sci \& Tech Res

CC (i) This work is licensed under Creative Commons Attribution 4.0 License

Submission Link: https://biomedres.us/submit-manuscript.php

$\begin{array}{ll}\text { BIOMEDICAL } & \text { Assets of Publishing with us } \\ \text { RESEARCHES } & \text { - Global archiving of articles } \\ \text { - Immediate, unrestricted online access } \\ \text { ISSN: } 2574-1241\end{array}$

